\title{
Pleomorphic Onychomatricoma: A Mimicker of Malignancy
}

\author{
Christophe PERRIN ${ }^{1,2}$ and Damien AMBROSETTI ${ }^{1}$ \\ ${ }^{1}$ Central Laboratory of Pathology, Hôpital Pasteur, University of Nice, Nice and 2Nail's Dermatology Consultations, Cannes, France
}

\begin{abstract}
Pleomorphic onychomatricoma is a rare condition mimicking malignant neoplasms. Given its rarity, the diagnostic and prognostic criteria of this condition are not well established. The aim of this study was to characterize a series of 6 cases of pleomorphic onychomatricoma. In 3 cases the submitting clinical diagnosis was subungual squamous cell carcinoma. For all 6 cases, nail clipping showed typical features of onychomatricoma as a free-edge thickening and pitting of the nail plate with an additional feature of projecting line pattern. Pleomorphic onychomatricoma was diagnosed based on moderate-severe cytological atypia, yet degenerative-appearing with multinucleation or smudged chromatin, no mitotic activity or necrosis, and a Ki67 proliferative index inferior to $5 \%$ overall. Other finding $s$ included epithelioid multinucleated cells with deeply eosinophilic cytoplasm mimicking epithelioid malignant cells, overexpression of Ki67 and p53 on atypical cells and diffuse expression of p16. This study describes additional criteria in pleomorphic onychomatricoma, permitting a wider recognition in order to avoid inappropriate treatment.
\end{abstract}

Key words: onychomatricoma; pleomorphic onychomatricoma; superficial CD34-positive fibroblastic tumour; superficial acral fibromyxoma; subungual squamous cell carcinoma; nail tumour.

Accepted Oct 25, 2021; Epub ahead of print Oct 25, 2021

Acta Derm Venereol 2022; 102: adv00628.

Corr: Christophe Perrin, Central Laboratory of Pathology, Hôpital Pasteur, University of Nice, Nice, France. E-mail: xst.perrin@bbox.fr

$\mathrm{P}$ leomorphic onychomatricoma (POM) is a rare condition that may mimic malignant neoplasms. To the best of our knowledge, 5 cases have been published (1-4), with 2 of them reported under the terminology of unguioblastic fibroma $(1,3)$. Given their rarity, diagnostic and prognostic criteria of POM are not well established. First, some authors (4) include, in the clinical presentation of POM, cases characterized by a distorted yellow nail plate lifted by thickened subungual keratosis, suggesting a clinical continuum between subungual pleomorphic fibroma and POM (4-6). Secondly, it remains to be determined whether the case reported by Ko et al. (1) actually belongs to the category of POM, as mitotic activity "was readily appreciable" and associated with focal necrosis. Such histological features are not completely in accordance with the experience of pleomorphic (symplastic) tumour in other organs.

In this case series we sought to further characterize the clinical, histopathological and immunohistochemical

\section{SIGNIFICANCE}

Pleomorphic onychomatricoma is a rare tumour mimicking malignancy. This study proposes diagnostic criteria for pleomorphic onychomatricoma that clinically include freeedge thickening and pitting pattern of the nail plate with an additional feature of projecting line pattern. Histologically, this benign condition is characterized by degenerative nuclear atypia, but with a superficial location in the stroma of the atypical cells, Ki67 proliferation rate inferior to $5 \%$, absence of mitotic figure or necrosis, and a distinctive immunophenotypical profile restricted to the diffuse expression of CD34 with focal or negative CD10 expression. Simple local excision appears to be adequate.

features of POM and to propose diagnostic criteria that exclude more aggressive neoplasm, including superficial CD34-positive fibroblastic tumour (SCFT) (7).

\section{RESULTS}

\section{Clinical data}

The clinical features of each patient are listed in Table I. The patients were 3 women and 3 men, ranging in age from 29 to 74 years (mean age 58.8 years). The known sites of involvement were right 2 nd finger in 2 cases, left $2^{\text {nd }}$ finger, right $4^{\text {th }}$ finger, left $4^{\text {th }}$ finger, and left $5^{\text {th }}$ toe.

Three cases presented an even thickening of the nail plate with, in 1 case (Fig. 1a), a fuzzy lateral border and in 2 cases (Fig. 1b) an irregular lateral edge of the nail lesion. Longitudinal xanthonychia band (2 cases) (Fig. 1a) or subtotal xanthonychia (1 case) (Fig. 1b) was associated with, linear and parallel white ridges and furrows, splinter haemorrhages, longitudinal and transverse nail plate overcurvature.

A frontal view of the free-edge of the nail plate (Fig. $1 \mathrm{~b}$, case 2) along with the nail clipping findings (Fig. $1 \mathrm{c}$, case 3) showed, in 2 cases, the typical feature of onychomatricoma (OM); namely a thickened nail plate with multiple small cavities. This free-edge pattern of the nail plate was initially termed a woodworm-like pattern of cavities (8) and, more recently, a thickening of the free-edge of the nail plate with pitting $(9,10)$. However, on dermoscopy or on analysis, at high magnification, of digital photography it was difficult to exclude subungual squamous cell carcinoma (SSCC) for 3 reasons. First, OM and SSCC share many clinical features, including xanthonychia, thickening and overcurvature of the nail plate, longitudinal parallel white lines, and splinter 
Table I. Summary of clinical, dermoscopic and nail clipping histological findings

\begin{tabular}{|c|c|c|c|c|c|c|c|c|c|}
\hline Case & $\begin{array}{l}\text { Age, } \\
\text { years/ } \\
\text { sex }\end{array}$ & Site & $\begin{array}{l}\text { Clinical } \\
\text { presentation }\end{array}$ & $\begin{array}{l}\text { Nail plate free- } \\
\text { edge examination }\end{array}$ & $\begin{array}{l}\text { Mean dimension of nail } \\
\text { plate thickening at its } \\
\text { distal edge }(\mathrm{mm})\end{array}$ & $\begin{array}{l}\text { Mean dimension of } \\
\text { cavities at the distal } \\
\text { edge }(\mathrm{H} \times \mathrm{V}, \mathrm{mm})\end{array}$ & $\begin{array}{l}\text { Duration } \\
\text { (years) }\end{array}$ & Treatment & $\begin{array}{l}\text { Recurrence/ } \\
\text { duration of } \\
\text { follow-up }\end{array}$ \\
\hline 1 & $74 / M$ & $\begin{array}{l}\text { Right } 2^{\text {nd }} \\
\text { finger }\end{array}$ & $\begin{array}{l}\text { Longitudinal } X \\
\text { and } T\end{array}$ & $\begin{array}{l}\text { Minor pattern: pits } \\
\text { Major pattern: } \\
\text { projecting line } \\
\text { pattern }\end{array}$ & 3.57 & $\begin{array}{l}\text { Minor pattern: } 0.43 \times 0.34 \\
\text { Major pattern: } 0.10 \times 0.49\end{array}$ & 3 & $\begin{array}{l}\text { Longitudinal } \\
\text { excision }\end{array}$ & No/4 years \\
\hline 2 & $46 / M$ & $\begin{array}{l}\text { Left } 5^{\text {th }} \\
\text { toe }\end{array}$ & Total $\mathrm{X}$ and $\mathrm{T}$ & Pits & 3.42 & $0.44 \times 0.44$ & $\begin{array}{l}\text { Extended } \\
\text { period of time }\end{array}$ & $\begin{array}{l}\text { Monobloc } \\
\text { excision }\end{array}$ & No/6 months \\
\hline 3 & $69 / F$ & $\begin{array}{l}\text { Left } 2^{\text {nd }} \\
\text { finger }\end{array}$ & $\begin{array}{l}\text { Longitudinal } \mathrm{X} \\
\text { and } \mathrm{T}\end{array}$ & Pits & 2.57 & $0.40 \times 0.61$ & 20 & $\begin{array}{l}\text { Longitudinal } \\
\text { excision }\end{array}$ & No/7 years \\
\hline 4 & $68 / F$ & $\begin{array}{l}\text { Right } 4^{\text {th }} \\
\text { finger }\end{array}$ & $\begin{array}{l}\text { Total } X \text { and } T^{*} \\
\text { suspected case } \\
\text { of SCC }\end{array}$ & Pits* & 1.42 & $0.47 \times 0.37$ & $\begin{array}{l}\text { Extended } \\
\text { period of time }\end{array}$ & $\begin{array}{l}\text { Monobloc } \\
\text { excision }\end{array}$ & No/20 years \\
\hline 5 & $67 / M$ & $\begin{array}{l}\text { Left } 4^{\text {th }} \\
\text { finger }\end{array}$ & $\begin{array}{l}\text { Longitudinal } X \\
\text { and } T^{*} \text { suspected } \\
\text { case of SCC }\end{array}$ & Pits* & 4 & $0.23 \times 0.29$ & 3 & $\begin{array}{l}\text { Longitudinal } \\
\text { excision }\end{array}$ & No/ 1 years \\
\hline 6 & $29 / \mathrm{F}$ & $\begin{array}{l}\text { Right } 2^{\text {nd }} \\
\text { finger }\end{array}$ & $\begin{array}{l}\text { Longitudinal } \mathrm{X} \\
\text { and } \mathrm{T}^{*} \text { suspected } \\
\text { case of SCC }\end{array}$ & Pits* & 2.85 & $0.45 \times 0.28$ & $\begin{array}{l}\text { Extended } \\
\text { period of time }\end{array}$ & $\begin{array}{l}\text { Longitudinal } \\
\text { excision }\end{array}$ & No/8 months \\
\hline
\end{tabular}

*Indirect clinical criteria provided by histological examination of the nail plate.

$\mathrm{X}$ : xanthonychia; T: thickening of the nail plate with overcurvature, longitudinal ridging, splinter haemorrhages and white dots; $\mathrm{H}$ : horizontal axis of the cavities; $\mathrm{V}$ : vertical axis of the cavities; SCC: squamous cell carcinoma; M: male; F: female.

haemorrhages (10). Secondly, as part of the criteria for differentiating OM and SSCC, fuzzy or non-parallel lateral edges of a nail lesion are considered more favourable criteria for SSCC (10). Thirdly, the features observed at the distal edge could be misconstrued as a pitted keratotic subungual mass surmounted by a slightly thickened yellow nail plate (Fig. 1b). Therefore, in these 2 cases, only nail clipping allowed a definite diagnosis of OM (Fig. 1c).

In 1 case (Fig. 2a, case 1), the small round-to-oval cavities filled with yellowish-to-brownish material were found only at the inferior portion of the free-edge of the nail plate, whereas the superior portion showed wavy ivory ridges separated by delicate furrows. This free-edge projecting line pattern corresponded, on nail clipping, to filiform cavities (Fig. 2b).

The intraoperative view, after removal of the nail plate, showed a small villous tumour originating from the matrix (Fig. 2c) and the typical sign of OM in the form of cavitation of the proximal edge of the thickened nail plate (Fig. 3a).

In 3 cases, no clinical information was given, other than a diagnosis of suspected SSCC. However, indirect clinical criteria were inferred from histological examination of the nail plate. In particular, histological examination of the distal part of the nail plate showed in all 3 cases, a thickened nail plate with small cavities as a pitting pattern (Fig. 3b, case 4, Table I).

The symptoms ranged in duration from 3 to 20 years. In 3 patients, the symptoms were extended over a long period that was unspecified. Among the treatment modalities were longitudinal excision of the tumour and en bloc excision of the nail apparatus. There was no evidence of metastatic disease or recurrent disease in any of the patients regardless of the treatment received.

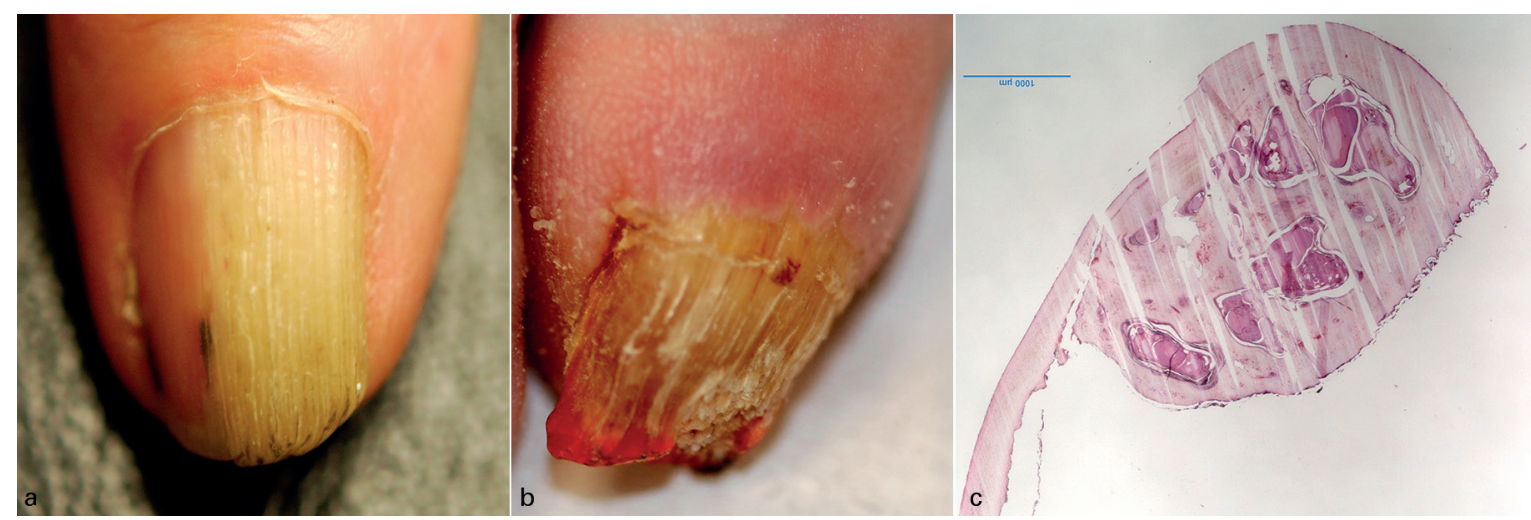

Fig. 1. Clinical presentation of pleomorphic onychomatricoma (POM) with a free-edge thickening and pitting pattern of the nail plate. Note that that dermoscopic criteria of onychomatricoma (OM) were equally visible on analysis, at high magnification, of classical photography under multiple camera angles. (a) Case 1. Longitudinal yellow nail band with longitudinal and transverse overcurvature. Nail plate examination showed the dermoscopic criteria of OM as alternating longitudinal yellow and thin white bands, white dots and foci of haemorrhage. (b) Case 2. Total xanthonychia with swelling of the proximal nail fold. En face free-margin view could be misconstrued as a pitted keratotic subungual mass surmounted by a slightly thickened yellow nail plate suggesting a diagnosis of subungual squamous cell carcinoma (SSCC). (c) Case 3 . Nail clipping examination reveals the typical feature of OM as a thickened nail plate marked by woodworm-like cavities or pits. In this case, the cavities were haphazardly arranged. 


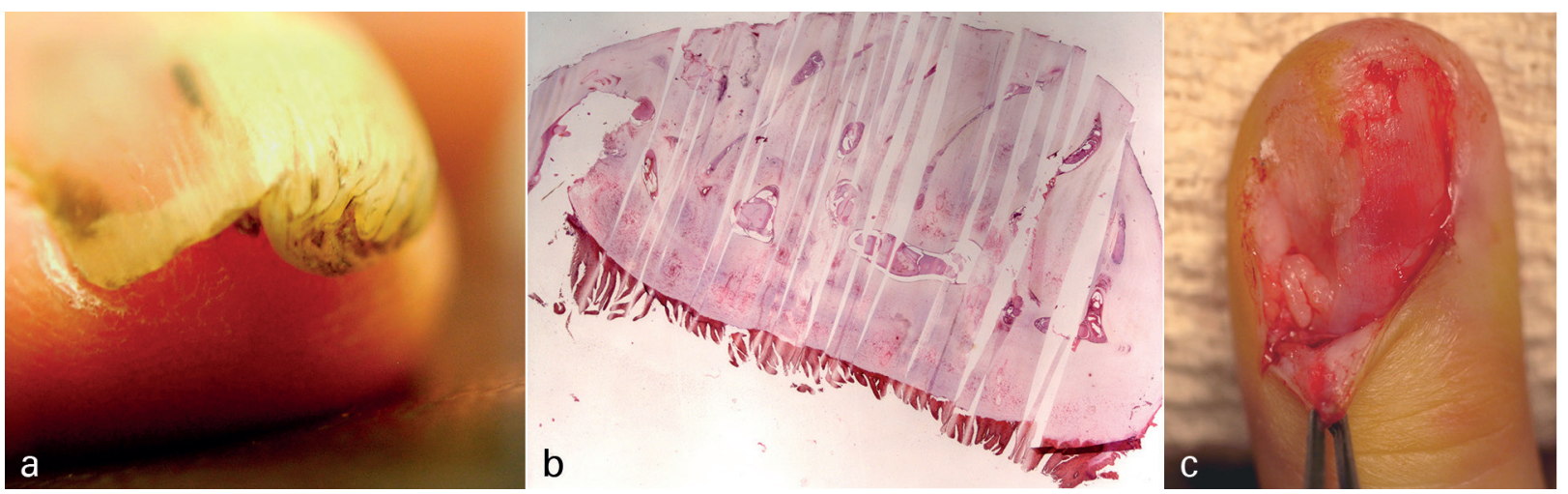

Fig. 2. Clinical presentation of pleomorphic onychomatricoma (POM) with a free-edge thickening and pitting pattern of the nail plate and an additional feature of projecting line pattern. (a) Case 1 . The pitting pattern of small cavities containing white-to-yellowish material was observed only at the inferior border of the nail plate, whereas the superior portion of the thickened nail plate showed wavy ivory ridges separated by delicate furrows of projecting line pattern. (b) Case 1 . The free-edge projecting line pattern corresponded, on nail clipping, to filiform cavities. (c) Case 3. Intraoperative view.

\section{Histopathological findings}

Specific nail clipping histological features of each patient are listed in Table I. In the 3 cases of the dermatopathology consultation file of 1 author (CP), diagnosis of atypical superficial acral fibromyxoma, pleomorphic fibroma vs low-grade sarcoma, dermatofibrosarcoma protuberans were offered by experienced dermatopathologists. Histology revealed the fibroepithelial architecture of an $\mathrm{OM}$ in all cases. The tumour showed either a pseudocondylomatous shape (1 case) (Fig. 3c), or a polypoid multibranched shape (5 cases) (Fig. 3d). Two stromal areas were prominent, even at a low magnifica- tion (Fig. 3d, e), including a superficial fibromyxoid area with wavy fibroblasts and a central area with thick collagen bundles running parallel to the axis of the tumour. The superficial mesenchymal component included in all specimens, spindle cells with moderate-tosevere atypia in the setting of a high nuclear/cytoplasmic ratio, yet with degenerative-appearing nuclear atypia with multinucleation or smudged chromatin (Fig. 3f, 4a). The multinucleated cells frequently presented a ring/floretlike arrangement of nuclei. Occasional multinucleated cells with vesicular nuclei, frequent nuclear overlap and abundant eosinophilc cytoplasm were seen in 1 case (Fig.
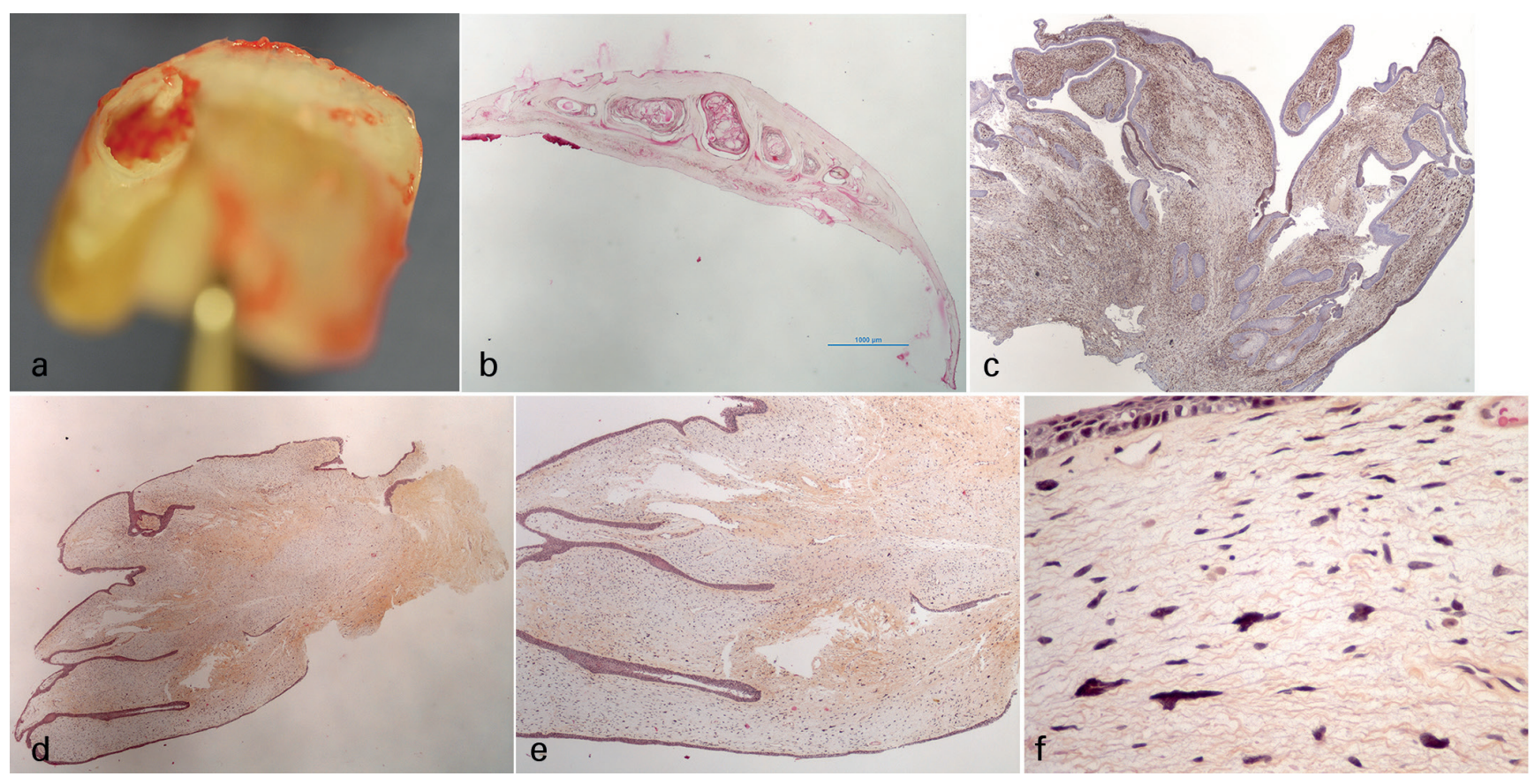

Fig. 3. Intraoperative view and histology. (a) Intraoperative view, note the typical sign of cavitation at the proximal border of the thickened nail plate. (b) Case 4 with a free-edge thickening and pitting pattern as the cavities were small with a cornified layer limiting their inner surface. In this case, the cavities were aligned in a horizontal axis. (c) p16 immunostaining $\times 20$; (d) haematoxylin and eosin (H\&E) $\times 20$; (e): H\&E $\times 40$ : low-power histological view, showing (c) a pseudocondylomatous architecture, or (e) a polypoid multibranched shape. (f) H\&E $\times 400$ : note atypical cells mainly located in the superficial oedematous to myxoid stroma. 


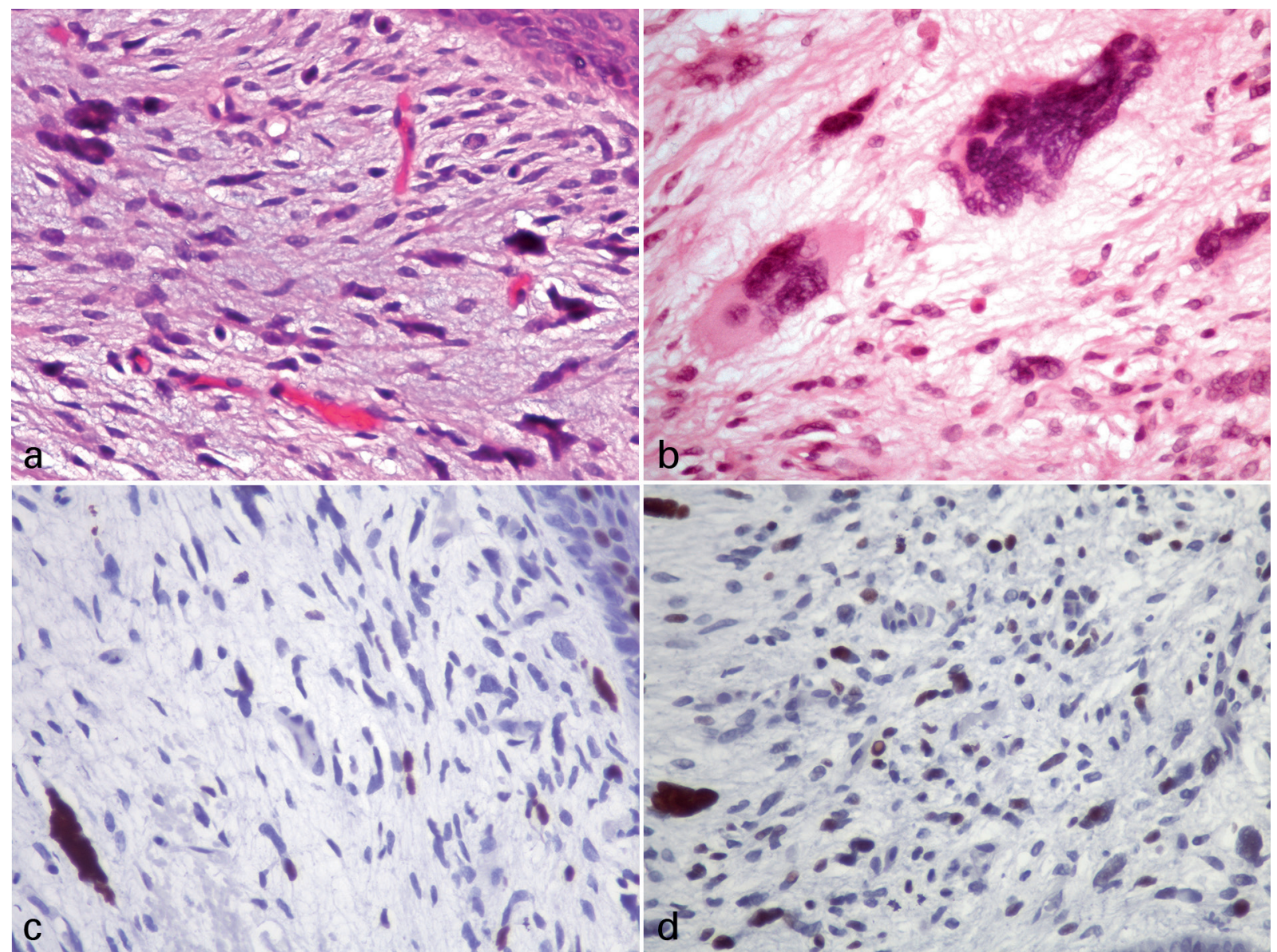

Fig. 4. High-power histological view (H\&E, orignal mgnification $\times 400)$ showing multinucleate cells with a floret-like arrangement of (a) nuclei and (b) an epithelioid feature. (c) Ki67 proliferative index in spindle cells is inferior to $5 \%$ overall, but approximately $20 \%$ in the large atypical cells. (d) Focal p53 overexpression on atypical cells.

4b). The density of atypical cells varied from being diffusely present (4 cases) (Fig. 3c, e) to focal atypical cells ( 2 cases). The stroma included many mast cells, which were easily identifiable in routinely stained sections. Mitoses, apoptosis or necrosis were consistently absent. Ki67 testing showed that the proliferative index was, overall, less than $5 \%$, but higher if the count was focused only on atypical cells (10-20\%) (Fig. 4c). There were 4 lesions with positive margins after longitudinal excision.

In order to gain more information concerning the differential immunohistochemical diagnosis between POM and subungual sarcomatous tumours, we expanded the panel of immunomarkers previously analysed in OM (2).

In all cases, CD34 was diffusely expressed, whereas CD10 expression was either moderate, $25-50 \%$ of neoplastic cells reactive (3 cases) or restricted to rare perivascular fibroblasts (3 cases). CD99, B-cell lymphoma 2 (bcl2), pancytokeratin, P63, epithelial membrane antigen (EMA), Glut-1, S-100protein, smooth muscle actin, desmin, Factor XIIIa, mucin 4 (MUC4), STAT6, and ALK1 failed to react with tumour cells of POM. Diffuse $\mathrm{p} 16$ expression on fibroblastic proliferation, with negative staining on epithelial and endothelial cells, was observed in all cases of POM (Fig. 3c). P53 staining was positive in 4 cases as focal expression (Fig. 4d), and negative in in 2 cases

\section{DISCUSSION}

POM is very uncommon and the diagnostic criteria have not been clearly defined in the literature. In the current study, through exhaustive analysis of both nail plate and the fibroepithelial core of the tumour, we were able to better define the clinical and histological feature of POM compared with OM.

The diagnostic of conventional OM can usually be established with confidence using the clinical criteria furnished by frontal view of the free-edge of the nail plate as a thickened nail plate with multiple large cavities in a honeycomb-like pattern (8). These cavities with a mean dimension of $1.13 \times 0.49 \mathrm{~mm}$ are visible either by naked eye, dermoscopy (8) or nail clipping (11). However, when the cavities are small (free-edge thickening and pitting pattern of the nail plate) it can difficult to establish clinically whether pachyonychia is caused by a thickened nail plate or by a localized band of subungual hyperkeratosis linked to subungual tumour, especially Bowen's disease 
$(10,12,13)$. Indeed, a study (10) using plate free-edge dermoscopy has shown that nail thickening and pitting are relatively frequently present in subungual squamous cell carcinoma (54.5\% and $18.2 \%$, respectively). Such diagnosis of squamous cell carcinoma was proposed in the 3 cases of the dermatopathology consultation file of 1 author (CP). In this instance, the definitive diagnosis of OM is made only by histopathology on nail clipping specimen or nail biopsy.

In the current case series the clinical spectrum of POM is clearly oriented toward this misleading pitting variant of OM, with the additional feature of filiform cavities in a projecting line pattern of the free-edge of the nail plate.

On histological grounds, this case series shows that POM, despite the presence of nuclear atypia, share histological features with conventional OM, including small size, low cellularity, lack of mitotic figures, and low Ki67 proliferation rate. Degenerative nuclear aypia with hyperchromatic smudgy chromatin was the defining feature of POM similar to subungual pleomorphic CD34 tumours family, including superficial acral fibromyxoma (SAF) and pleomorphic fibroma $(\mathrm{PF})(5,6,14)$. Troubling findings of this study were the presence of epithelioid multinucleated cells with deeply eosinophilic cytoplasm mimicking epithelioid malignant cells, overexpression of Ki67 and p53 on atypical cells, and diffuse expression of $\mathrm{p} 16$.

Detailed description of the pathological features of the nail plate in OM has been published $(2,11-13)$. Despite this, without pertinent clinical information, OM still represents a diagnostic challenge for pathologists. Indeed, in the current case series, the submitting pathologists do not suggest OM. Conversely, when the avulsed nail plate is not received by the dermatopathologist, which is a frequent occurrence in recent recruitment to our patient population due to the development of shave biopsy in nail surgery, it may be difficult to distinguish POM from other CD34 fibrous neoplasms. After nail plate avulsion, the keratogenous zone remains adherent to the nail plate. Therefore the matrix differentiation of the epithelial component is sometimes difficult to assess histologically, and a reliable diagnosis is not possible without a large panel of immunohistochemical markers.

The histopathological differential diagnosis for POM mainly includes pleomorphic SAF (14) and its fibrous variant, pleomorphic perineuromia, cellular angiofibroma and superficial ALK-rearranged myxoid spindle cell neoplasm. SAF (14) shares many morphological features with POM, including, clinically, a subungual location, and, histologically, an epithelial component with papillary digitations bizarre-appearing cells, and a generally low mitotic activity, but typically express CD99 with a focal reactivity for EMA. By definition, perineurioma express EMA and Glut-1, whereas POM is negative for these 2 markers. Cellular angiofibroma (15) is ruled out by its striking hyalinized vessels, the absence of a biphasic pattern of its stroma, and focal staining for bcl2. Superficial ALK-rearranged myxoid spindle cell neoplasm (16) is typified by a diffuse expression of ALK1 and a frequent expression of S100 protein.

In the differential diagnosis, one must also consider the CD34-positive fibrosing sarcomatous family.

POM share multiple histological features with SCFT, including a multibranched fibrokeratoma-like architecture, nuclear atypia with epithelioid cells, lack of mitotic activity and low Ki67 proliferative index (7). Keratin immunoreactivity is a helpful feature, because it is present in $\operatorname{SCFT}(7,17)$ and absent in POM. We also observed that POM cells were predominantly located in the superficial layer of the stroma, which might be of additional diagnostic value as atypical cells are diffusely present in the stroma of SCFT.

Myxoinflammatory fibroblastic sarcoma share some morphological feature with POM, including bizarreappearing cells in a myxoid stroma, a generally low mitotic activity and a acral location, but typically contains cells with prominent nucleoli, prominent inflammatory infiltrate and perivascular hyalinization.

Dedifferentiated solitary tumour (18) show p53and p16 overexpression in its discrete anaplastic component, but exhibits a specific positivity for STAT6 and low-grade fibromyxoid sarcoma express Muc4.

Pleomorphic dermatofibrosarcoma is a highly infiltrative spindle cell neoplasm characterized by increased proliferative index, diffuse expression of bcl2, higher expression of $\mathrm{p} 53$, and decreased positivity for CD34 $(19,20)$.

In the current study, the p16 overexpression in all tumours and focal overexpression of p53 in 4 tumours are in keeping with the potential role of p16 and p53 in the process of atypia as degenerative ageing phenomenon previously identified in pleomorphic fibroma (21). The underlying genetic aberration remains to be elucidated (unpublished data).

In summary, we propose diagnostic criteria for POM that clinically include, free-edge thickening of the nail plate with a pitting pattern and an additional feature of projecting line pattern. Histologically, this benign condition is characterized by degenerative nuclear atypia, but with a superficial location of the atypical cells, Ki67 proliferation rate inferior to $5 \%$, absence of mitotic figure or necrosis and a distinctive immunophenotypic profile restricted to the diffuse expression of CD34 with focal or negative CD10 expression. Simple local excision or "shelling out of the lesion" appears to be adequate and effective to avoid recurrences and injuries to the surrounding tissue.

\section{ACKNOWLEDGEMENTS}

The authors thank Arnaud Borderie and Marianne Goracci for technical assistance and the following clinician who has kindly 
provided case material and clinical follow-up information: Dr G. E. Cannata, Imperia, Italy (case 2) and Dr C. Dumontier, Nice, France (case 3).

The authors have no conflicts of interest to declare.

\section{REFERENCES}

1. Ko CJ, Shi L, Barr RJ, Mölne L, Ternesten-Bratel A, Headington JT. Unguioblastoma and unguioblastic fibroma - an expanded spectrum of onychomatricoma. J Cutan Pathol 2004; 31: 307-311.

2. Perrin C, Baran R, Balaguer T, Chignon-Sicard B, Cannata GE, Petrella $T$, et al. Onychomatricoma: new clinical and histological features. A review of 19 tumors. Am J Dermatopathol 2010; 32: 1-8.

3. Petersson F, Tang ALY, Jin ACE, Barr RJ, Lee VK. Atypical cellular unguioblastic fibroma. A rare case with more atypical histological features than previously reported. Am J Dermatopathol 2010; 32: 387-391.

4. Fernandez-Flores A, Barja-Lopez JM. Pleomorphic onychomatricoma. J Cutan Pathol 2014; 41: 555-560.

5. Hassanein A, Telang G, Benedetto E, Spielvogel E. Subungual myxoid pleomorphic fibroma. Am J Dermatopathol 1998; 20: 502-505.

6. Hsieh YJ, Lin YC, Wu YH, Su HY, Billings ST, Hood AF. Subungual pleomorphic fibroma. J Cutan Pathol 2003; 30: 569-571.

7. Perrin C Pedeutour F, Dadone-Montaudié B, Ambrosetti D. Superficial CD34-positive fibroblastic tumor: case report of an unique subungual presentation with confounding clinical findings resembling fibrokeratoma-like Bowen's disease. Acta Derm Venereol 2021; 101: adv00388.

8. Di Chiacco N, Tavares GT, Tosti A, Di Chiacco NG, Di Santis E, Alvarenga $L$, et al. Onychomatricoma: epidemiological and clinical findings in a large series of 30 cases. Br J Dermatol 2015; 173: 1305-1307.

9. Lesort C, Debarbieux S, Duru G, Dalle S, Poulhalon N, Thomas L. Dermatoscopic features of onychomatricoma: a study of 34 cases. Dermatology (Basel) 2015; 231: 177-183.

10. Teysseire S, Dalle S, Duru G, Phan A, Debarbieux S, Poulhalon $\mathrm{N}$, et al. Dermatoscopic features of subungual squamous cell carcinoma: a study of 44 cases. Dermatology (Basel) 2017; 233: 184-191.
11. Perrin C, Cannata GE, Langbein L, Ambrosetti D, Coutts M, Balaguer T, et al. Acquired localized longitudinal pachyonychia and onychomatrical tumors: a comparative study to onychomatricomas (five cases) and onychocytic matricomas (four cases). Am J Dermatopathology 2016; 38: 664-671.

12. Perrin $\mathrm{C}$. Onychomatricoma micropapilliferum, a new variant of onychomatricoma: clinical, dermoscopical and histological correlation; (report of 4 cases). Am J Dermatopathol 2020; 42: $103-110$.

13. Perrin C, Ambrosetti D, Balme B, Thomas L. Clinical, dermoscopical, and pathologic feature of onychomatricoma new variant ressembling onycholemmal/squamous cell carcinoma. Am J Dermatopathol 2020; 42: 827-834.

14. Hollmann TJ, Bovée JV, Fletcher CD. Digital fibromyxoma (superficial acral fibromyxoma): a detailed characterization of 124 cases. Am J Surg Pathol 2012; 36: 789-798.

15. 15.Perrin C, Cannata GE, Pedeutour F, Dadone-Montaudié B, Ambrosetti D. Cellular angiofibroma: a case report of a unique subungual presentation. Acta Derm Venereol 2019; 19: 915-916.

16. Dermawan JK, Azzato EM, Golblum JR, Rubin BP, Billings SD, KO JS. Superficial ALK-rearranged myxoid spindle cell neoplasm: a cutaneous soft tissue tumor with distinctive morphology and immunophenotypic profile. Modern Pathol 2021; 34: 1710-1718.

17. Perret R, Michal M, Carr RA, Velasco V, Svajdler M, Karanian $M$, et al. Superficial CD34-positive fibroblastic tumor and PRDM10-rearranged soft tissue tumor are overlapping entities: a comprehensive study of 20 cases. Histopathology 2021; 79: 810-825.

18. Mosquera JM, Fletcher CD. Expanding the spectrum of malignant progression in solitary fibrous tumors. Am J Surg Pathol 2009; 33: 1314-1321.

19. Shah KK, Mc Hugh JB, Folpe AL Patel RM. Dermatofibrosarcoma protuberans of distal extremities and acral sites. A clinicopathologic analysis of 27 cases. Am J Surg Pathol 2018; 42: 413-419.

20. Suster S, Fisher C, Moran CA. Expression of bcl2 oncoprotein in benign and malignant spindle cell tumor of soft tissue, skin, serosal surface and gastrointestinal tract. Am J Surg Pathol 1998; 22: 863-872.

21. Hinds B, Pérez ADA, LeBoitPE, Mc Calmont TH, North JP. Loss of retinoblastoma in pleomorphic fibroma: an immunohistochemical and genomic analysis. J Cutan Pathol 2017; 44: 665-671. 